\title{
A Study on Strategic Initiative for Reinvigorating Employee Engagement among Gen $\mathrm{Z}$
}

\author{
Dr. R. Jayanthi ${ }^{1}$, Dr. Soney Mathews ${ }^{2}$ \\ ${ }^{1}$ Acharya Bangalore B School \\ ${ }^{2}$ St. Joseph College of Commerce, Bangalore
}

\begin{abstract}
Background/objectives: Gen $\mathrm{Z}$ are already in the workforce today, being a tech savvy Gen they have bought new perspectives and expectations at the workplace. The objective of this paper is to understand what are the factors that govern engagement of Gen $\mathrm{Z}$ at the workplace? and to know the correlation of these factors on employee engagement.
\end{abstract}

Method/ analysis: Literature review is basis for developing the hypothesis of the study, thorough study of research papers helped in identifying the common factors mentioned, MS Excel was used to analysis the data that was collected. Correlation co-efficient and regression are the statistical tools used.

Findings: All the factors identified have a positive correlation with organizational performance and employee engagement of Gen Z. Career development and Rewards and recognitions were the two important factors identified.

Application: This paper throws light on the policy changes that has to been done to accommodate the young work force who are ready to join and have diverse expectations of a work place, failing which companies may find it difficult to attract, retain and engage Gen $\mathrm{Z}$ in the days to come.

Key Words: Gen Z, Factor Analysis, Career Development, employee engagement, diverse expectations. 